\title{
Tumores de la lengua en el niño
}

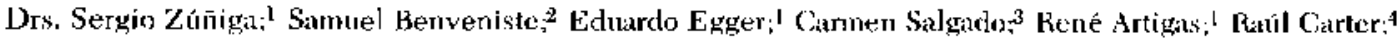 \\ Sira. Ana María Torres 5
}

Tumors of the tongue in children

\begin{abstract}
Benign and majignant tumors of the tongute seen in a Surgical Pediatric Service, are presented and analized, in a lupse of five years, from 1976 to 1981.

This repore includes at thahdinnyesarcotiat, pakrly clescribed lession which we managed with gools rexulti,

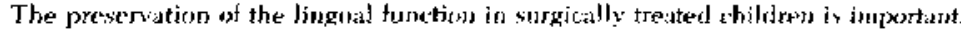

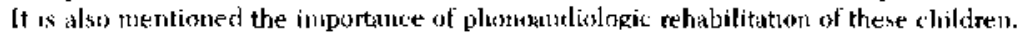

Es habitual que el cirujano pediatra este familiarizado con la cirugia de lengua, pero principalmente en su aspecto traumático, dado que las lesiones de este tipo son bastante comunes en los nin̄os. Las técnicas de reparación son sencillas y los resultados muy satisfactorios, como consecuencia de la rica vascularización lingual.

Otra variedad de lesión no tan frecuente de ver, es la tumoral. Su diagnóstico clínico, en ocasiones, es bastante dificil, ya que muchas de ellas presentan características comumes. De ahi la importancia que tiene el estudio anátomo-patolígico de las zonas resecadas, que no rara vez revela sorpresas. La cintgia de estas lesiones debe ser cuidadosamente planeada, considerando la variedad de funciones que la lengua posee, evitandose de esta manera secuelas futuras.

Desde 1976 a la fecha, los casos de patología tumoral lingual, operados en el Servicio de Cirugía Pediátrica del Hospital Exequiel González Cortés, han sido analizados y algunos de ellos son expuestos en consideración a su trecuencia y forma de presentación.

\section{MATERIAL Y METODO}

Los casos clínicos se han clasificado siguiendo el esquema preconizado por Jones y Campbell. ${ }^{4}$

\footnotetext{
IServicio de Cinngia Pediátrica. Huspital E. González Cortés. Depto. de Pediatría y Cirugla Infanti Snr. Facultad de Medicina. Lniversidad de Chile.

${ }^{2}$ Scrvicto de Anatomia Patólogicas. Hixpital Exequiel Gonzalez Cortés.

${ }^{3}$ Unidad de Onculogíu. Hospital Exeguiel González Cartéx.

4 Radioterapia Infantil. Servicio de Oncologia. Hempital San José.

Fonoadidiologia Servición de Cinupia Pediátrica. Hospitul Exeyuiel González Contés.
}

Con el patrucin io del Gnipn Oncológico Cooperativo Pediátrico Chileno (G.O.P.E.C.HI.)

\section{A. LESIONES BENIGNAS}

1. Linfongioma: Son relativamente frecuentes, variando de estructuras de aspecto quístico (Fig. 1), ubicadas en el dorso de la lengua y que nu requieren mas que una resección "en cuna", a lesiones difisas que forman parte de un higroma quístico cervical (Fig. 2) y que infiltran la totalidad de la lengula con producción de una macroglosia tan extrema como para impedir la inclusión lingual en la cavidad oral (Fig. 3). Muchos de estos casos requieren traqueostomía urgente en período neonatal; asimisino su alimentación sólo es posible a través de ura sonda naso-gástrica.

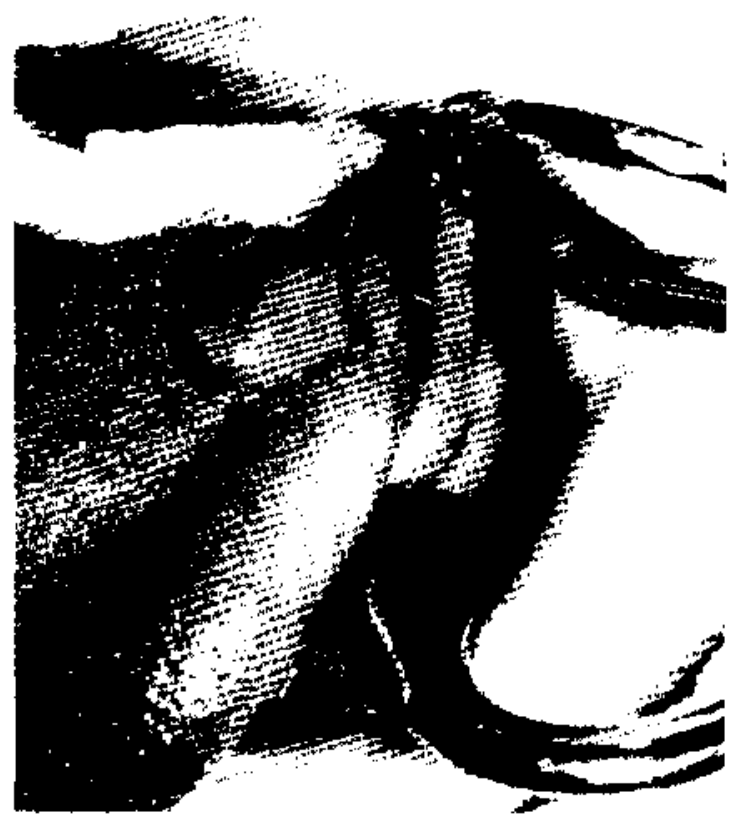

Figura 1. Linfungiona quístico en derso lingual. 


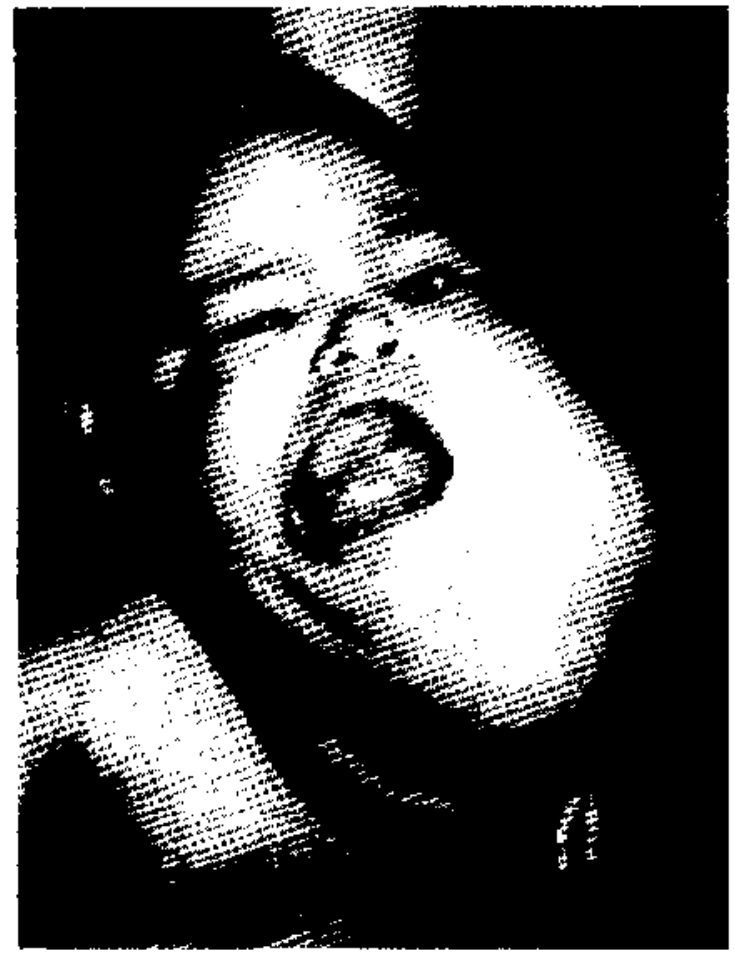

Figura 2. Higrona tuistico cervical con compromiso extenso de la lengua.

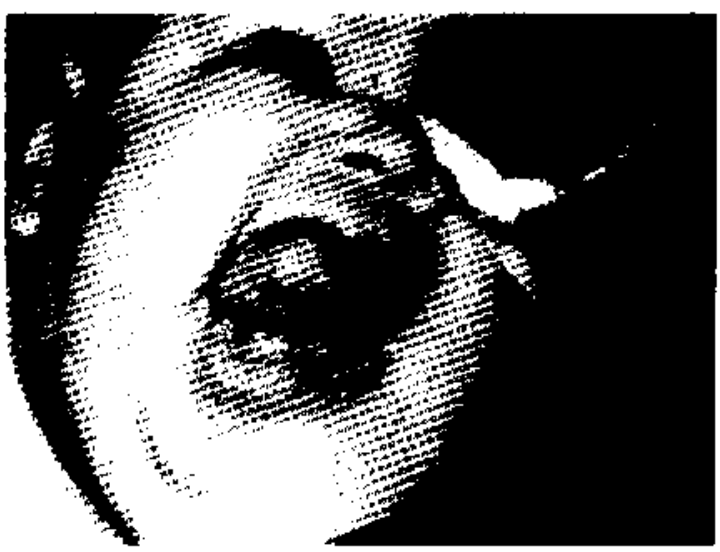

Figura 3. Paciente iuego de la extinpación parcial del higroma quísicocersical.

En la paciente de la figura 2, fue extirpado parcialmente el higroma quísticu cervical, realizándose posteriormente una hemiglosectomía parcial. El estudio histológico de la zona extirpada (Fig. 4), mostró cavidades linfáticas de diferentes diámetros, comprometiendo corion y tejido conjuntivo intersticial de musculo, desplazando a éste.

En la figura 5 se aprecia el aspecto postoperatorio tardio de la paciente.

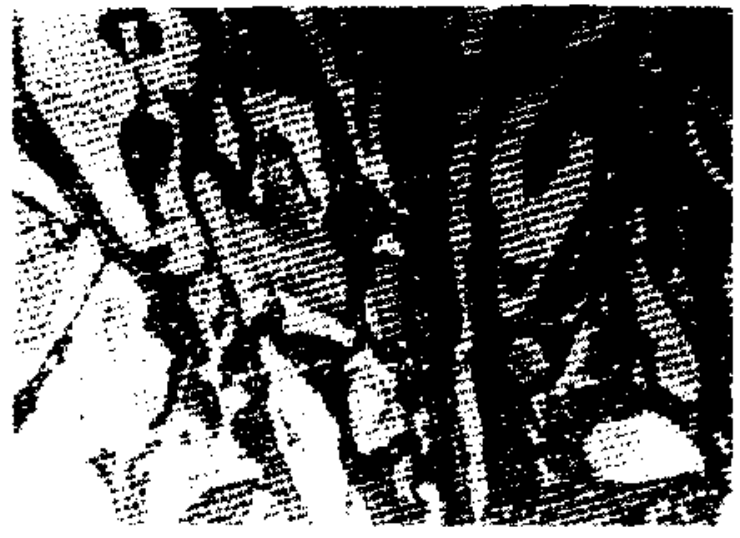

Figuma 4. Histología de lintangioma lingual.

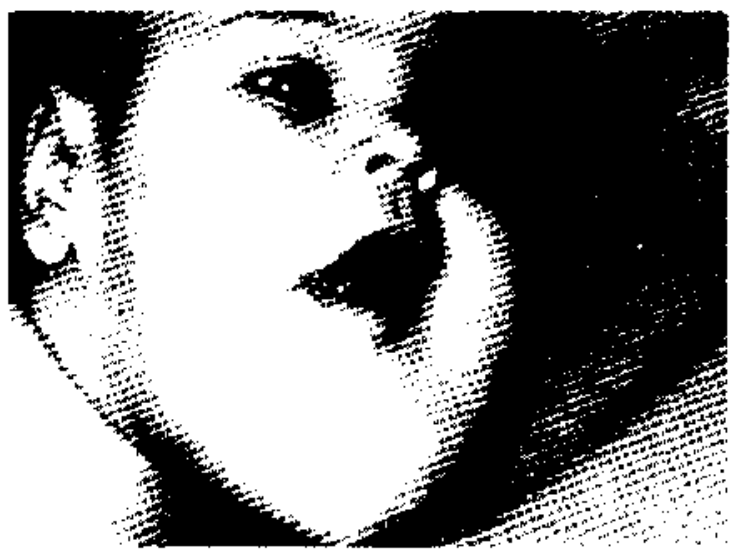

Figura 5. Aspecto post npe ratorio tardio de la pacieulte.

Los linfangiomas pueden existir desde el períndo neonatal o hacer su aparición más tarde. $\mathbf{E}_{\mathbf{n}}$ general se dice, que más de un tercio de ellos están presentes antes de los seis añus. En estos casos a veces se ponen de manifiesto por episodios recurrentes de glositis y tumefacción de la lengua (Fig. 6), cuya superficie está poblada por nódulos irregulares de color gris o rosado. El estudio de la biopsia en este caso reveló un linfangioma lingual con signos de infección bacteriana.

El tratamiento en este niño es el de la infección, adoptándose una conducta expectante respecto al linfángioma.

2. Hemangioma: Pueden ser localizados o difusos; en general producen macroglosia con menor frecuencia que el lintangioma, del que se diferencian por el color rojo vivo y su tendencia a sangrar.

En la figura 7 se aprecia una tumoración irregular en dorso lingual, de superficie externa hemorrágica. Luego de extirpada, la histología (Fig. 8) muestra gran cantidad de vasos sanguíneos capi- 

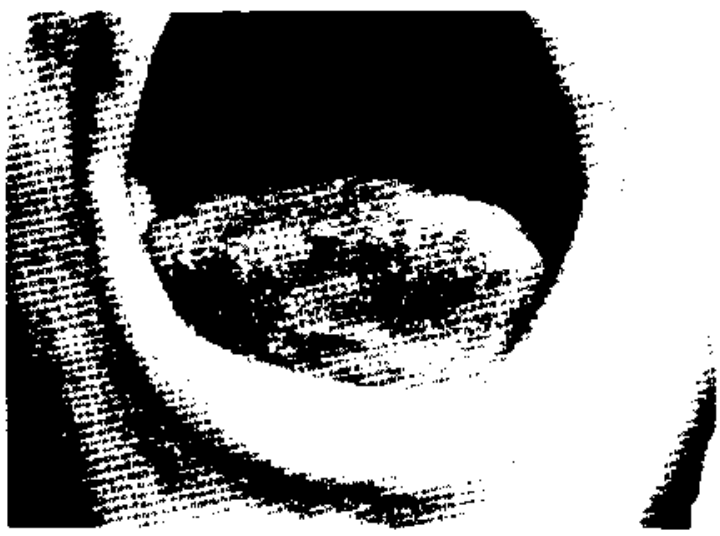

Figura 6. Linlangiona lingual con signons de intección bacteriana.

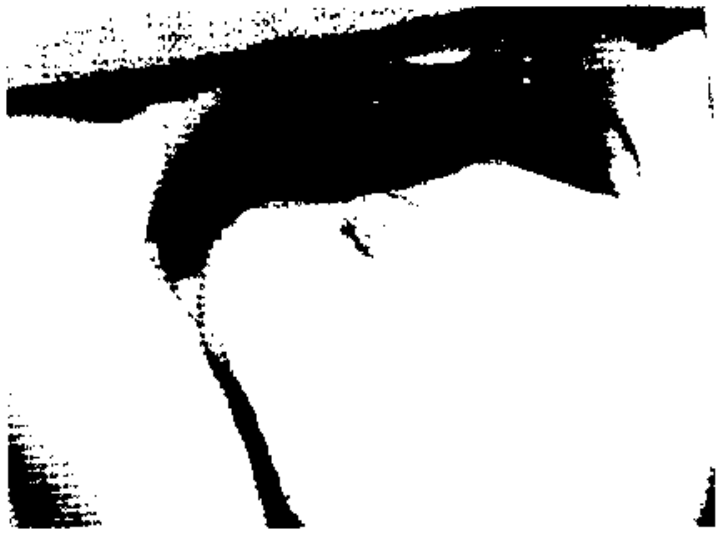

Figura 7. Hentangioma de dorso lingual.

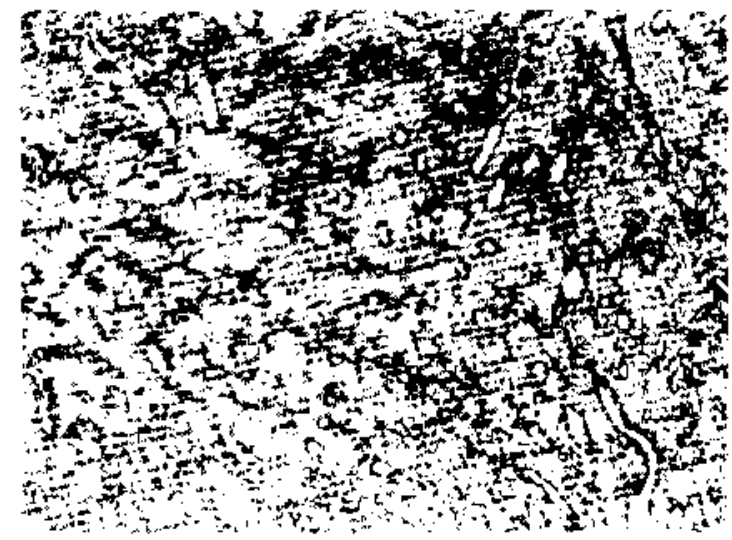

Figura 8. Histologia del proce yo anterior.

lares de diferente diámetro que comprometen corion.

3. Neurofibroma: Puedes ser causa de macroglosia unilateral (Fig. 9). Generalmente se asceian a neurofibromas de la piel y manchas de color "café con leche". Son relativamente avasculares y no compresibles. Estas neoplasias tienden a no ser encapsuladas y a extenderse hacia el suelo de la boca, por lo que la cingía suele ser dificultosa. En la paciente de la figura se efectuo una reducción anterior y lateral izquierda lingual. El estudio histológico (Fig. 10) de las zonas extirpadas reveló tumoraciones constituidas por termimaciones nerviosas y tejido colágeno, que comprometran co rion y tejido conjuntivo intersticial de músculo, desplazando a éste.

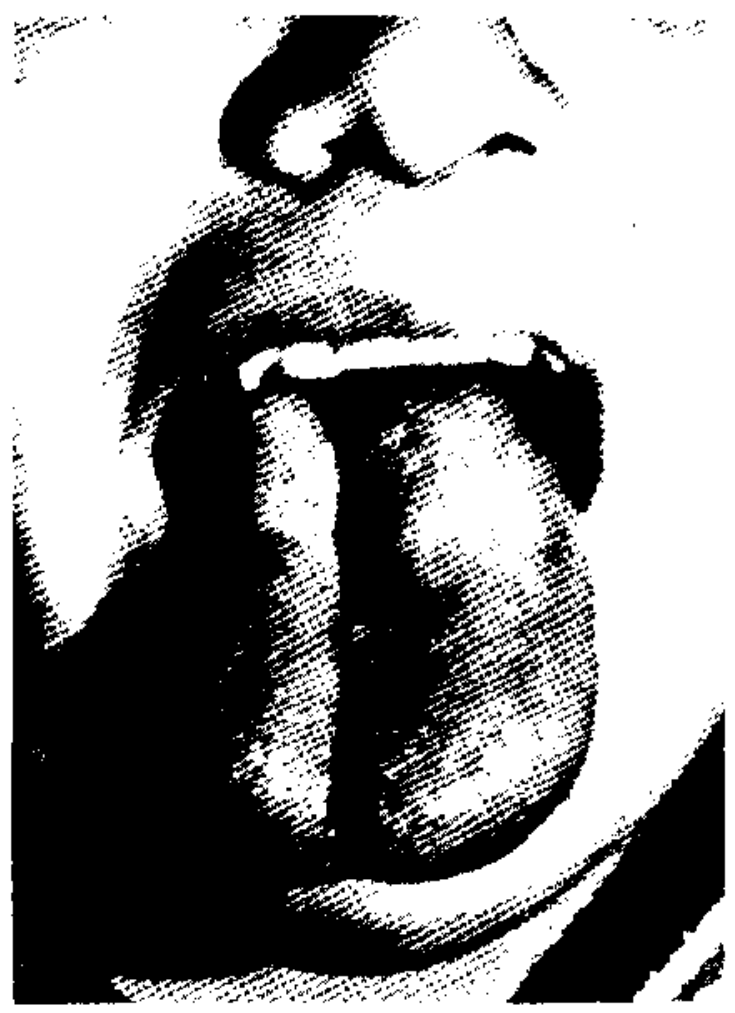

Figura 9. Macroglosia unilateral izupierda por neturofibroma.

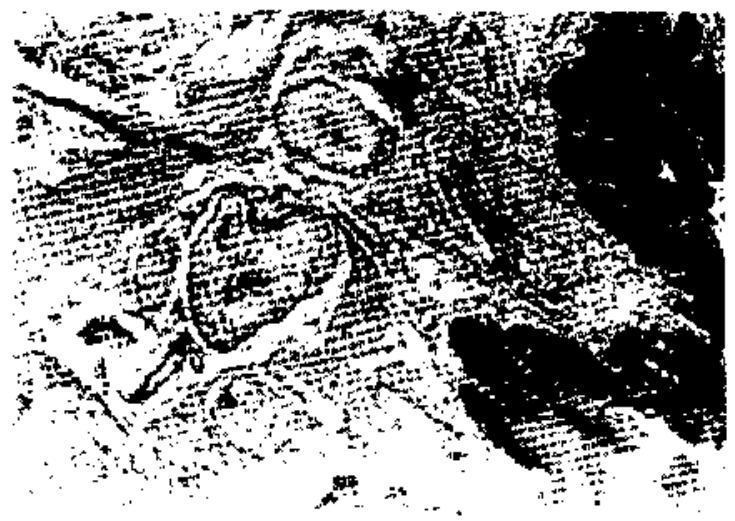

Figura 10. Aspectu microscopico de neumfibronatosis lingual. 
En la figura 11 se aprecia el postoperatorio tardio de la paciente.

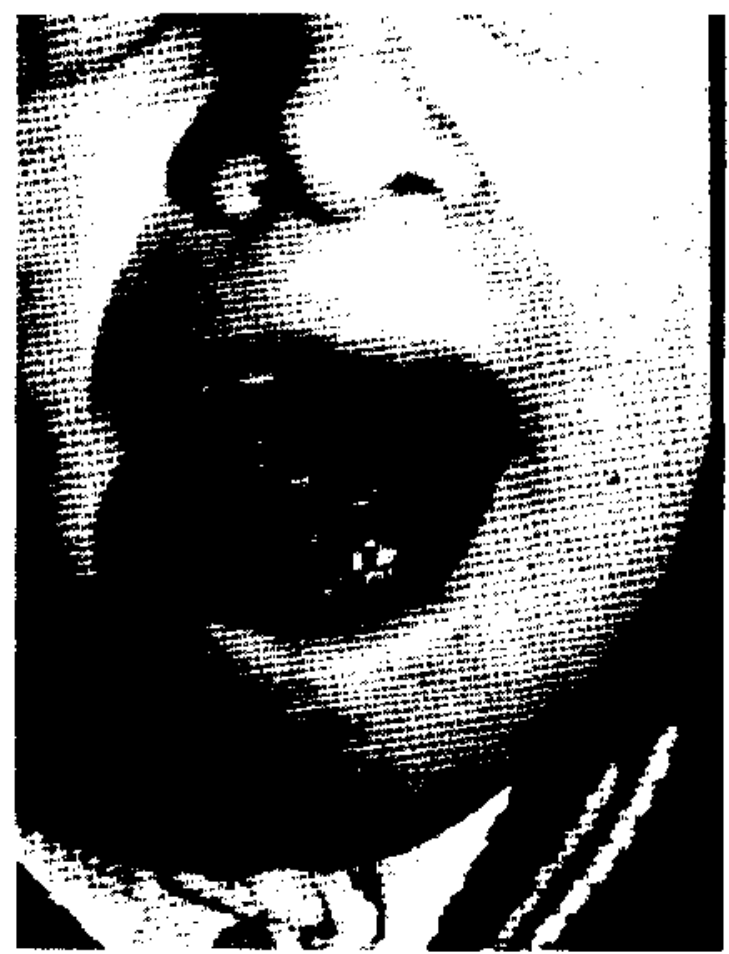

Figura 1 1. Postoperatorio tardio de la paciente de la figura 9.

Un caso de neurofibroma lingual digno de mención, es el de un niño de ocho años de edad, que consultó por una tumoración irregular, de crecimiento lento, ubicada en la línea media, en la unión del tercio medio con el tercio posterior (Fig. 12). La superficie de esta masa era lisa y su color amarillento y la evolución aproximada era de un año, $\sin$ haber causado molestias, excepto e] aumento de volumen ya descrito, que muy ocasionalmente obstaculizaba la deglución, La extirpación quirürgica no presentó problemas. El estudio histológico reveló un tumor que comprometía el corion y estaba constituido por fibras colágenas entremezcladas con finas terminaciones nerviasas. la evolución posterior del niño ha sido satisfactoria.

4. Quiste de retención de glándula mucosa lingual: Su tamaño coma la edad en que pueden aparecer, son variables. Muy ocasionalmente producen alguna sintomatología, dependiendo del volumen que alcancen. El tratamiento es quirurgico y consiste en la extirpación completa.

En la figura 13, se aprecia una tumoración de aspecto quístico en la región anterior inferior linyual. Una vez extirpada, la histología (Fig. 14) revela una cavidad ruística localizada a nivel de músculo lingual y limitada por epitelio plano estratificado y tejido fibroso.

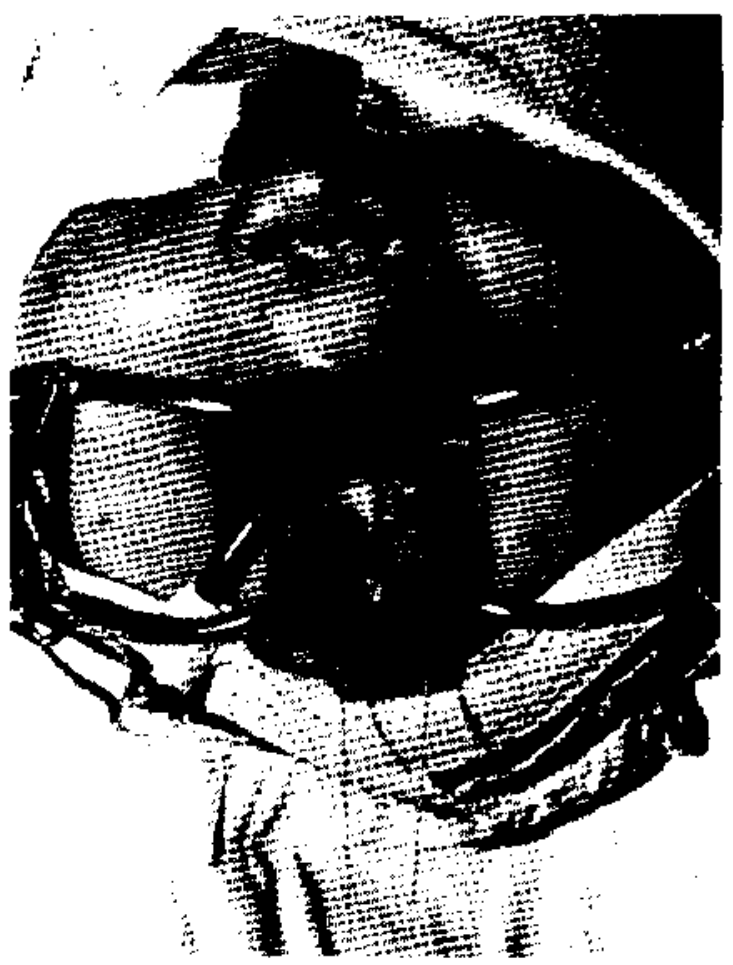

Figura 12. Neurofibroma de línea media lingual.

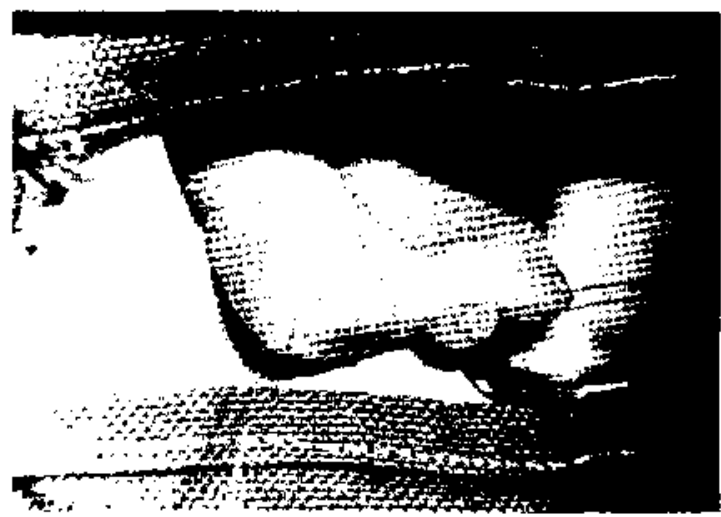

Figura 13. Quiste mucoso lingual.

5. Ránula: No se trata propiamente de una lesión lingual; sin embargo, puede producir compromiso funcional de la lengua, por el crecimiento que experimenta desde el piso de la boca, lugar donde se origina. La etiología de este proceso está en la 


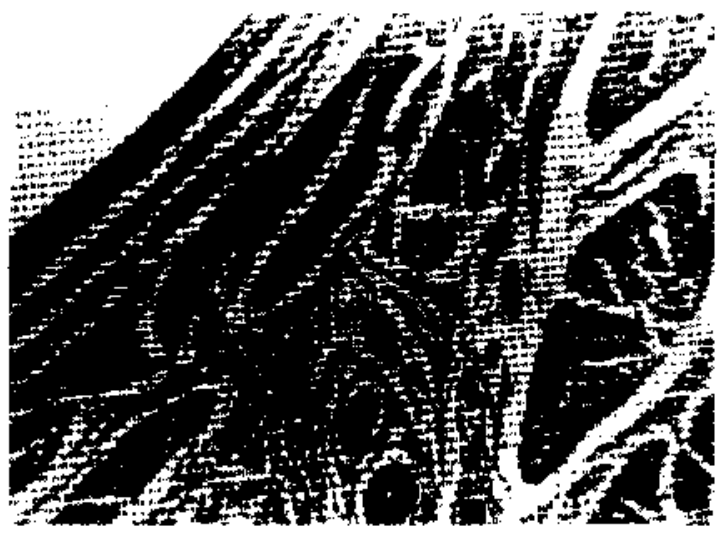

Figura 14. Aspecto urjeroscópico del proxeso interior.
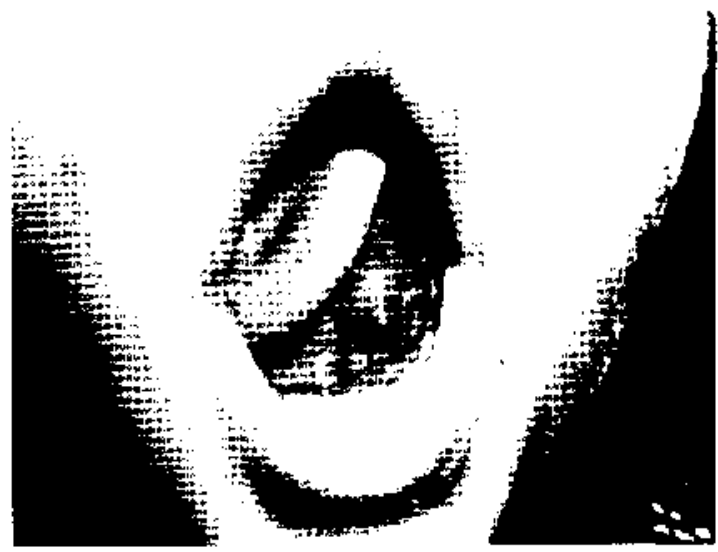

Figura 15. Ránula.

obstrucción de una de las glándulas salivales sublinguales (Fig. 15).

Desde el punto de vista histológico, la ránula es una pared quistica revestida de epitelio. El contenido del quiste es mucoso.

El tratamiento quirúrgico tradicional en el niño, es la marsupialización, en los castos en que no se logra su extirpación completa.

\section{B. LESIONES MALIGNAS}

Rabdomiosarcoma lingual: El rabdomiosarcoma és uno de los tumores sólidos frecuentes en la infancia; sin embargo, la lengua no es un sitio común para su localización. ${ }^{2,7}$ De 63 rabdomiosarcomas de cabeza y cuello en niños, en una serie de la Clinica Mayo, sólo 3 se originaron en la lengua? La clinica descrita clásicamente en estas lesiones, es la de una masa de crecimiento rapido, que puede ulcerarse y sangrar. De acuerdo al tamaño, se presentarán dificultades al tragar o respirar.
El caso atendido en nuestro servicio, era el de una niña de 7 ańus, sin antecedentes previos de importancia, que presentaba una tumoración lingual lateral izquierda, de aproximadamente 3.0 cm de diámetro, cuya superficie era algo irregular, de color amarillento y ligeramente ulcerada. Al momento de consultar, tenía una evolución aproximada de treinta dias.

El examen físico y los estudios habjtuales de laboratorio en el período preoperatorio, eran normales. La palpación lingual revelaba compromiso profundo por el tumor y el acto quirúrgico consistió en la extirpación completa de la masa, con tejido circundante de aspecto sano.

La histología reveló un tumor no circunscrito, que comprometía el corion y el músculo, provocando ulceraciones del primero; constituido por células pequeñas, redondeadas, de núcleo picnótico y escaso citoplasma, altemando con otras de aspecto fusiforme, de diferentes diámetros y núcleos vesiculosus. (Figs. 16 y 17 ).

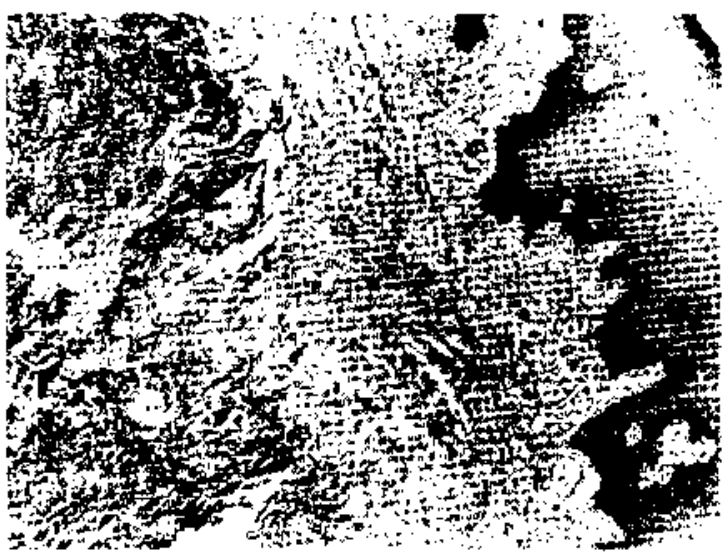

Figura 16. Rabdomiosarcoma lingual. Aspecto inicroscópico.

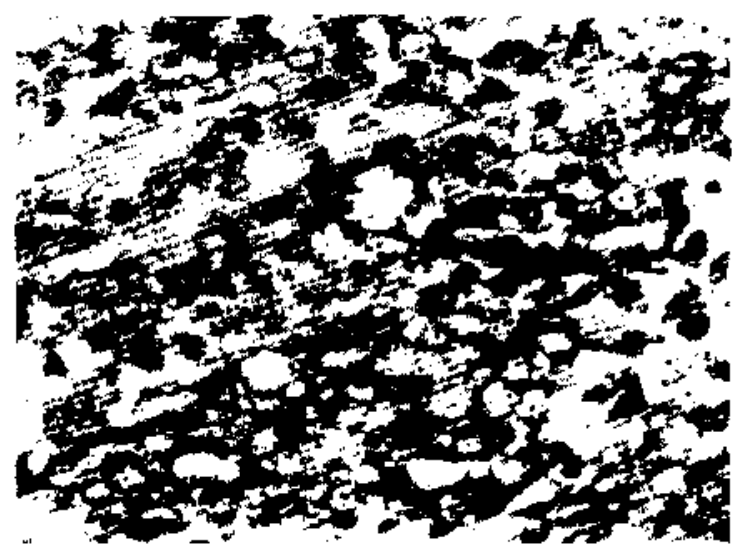

Figura 17. Rabdomiosarcoma lingual. Aspecto microscópico. (mayor aumento). 
Confirmado el diagnóstico de rabdomiosarcoma embrionario, ulcerado, infiltrante, la paciente fue tratada con quimioterapia múltiple, (Vincristina, Actinomicina-D, Ciclotosfamida y Adriamicina) por un período de dos años, según protocolo de tratamiento de sarcomas de partes blandas, además de radioterapia, recibiendo una dosis total de 6.000 rads en la zona.

La evolución hasta el momento ha sido satisfactoria, ya a tres años del diagnóstico, sin evidencias clínicas de enfermedad ni secuelas derivadas del tratamiento. (Fig. 18).

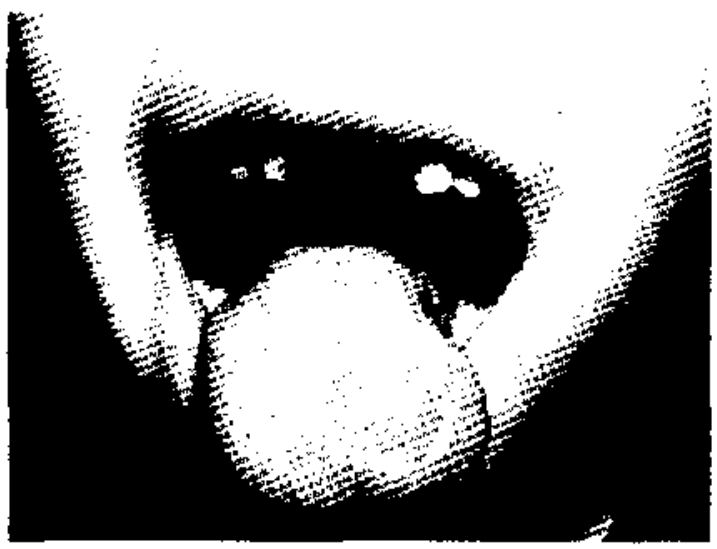

Figura 18. Rabdomiosarconua lírugual. Postoperatorio tardio.

Este caso será objeto de una publicacionn más detalladiz en el futuro.

\section{COMENTARIO}

La primera comunicación de una extirpación quirúrgica por un cáncer lingual, fue realizada en 1664; $;^{3}$ sin embargo, la revisión de la literatura especializada hasta la fecha, no es mucho lo que aporta sobre lesiones tumorales de lengua, menos aún en niños.

La presente recopilación, en un periodo de cinco años, ha permitido reunir una notable casuística de lesiones de este tipo, en la infancia, encontrándose incluso un rabdomiosarcoma, tumor maligno de muy baja frecuencia en la lengua. ${ }^{6.9} \mathrm{En}_{\mathbf{n}}$ relación a este, es gratificante su excelente evolución hasta el momento, como fruto de un trabajo multidisciplinario bien enfocado. En general en pronóstico de los rabdomiosarcomas de cabeza y cuello en niños, no es bueno ${ }^{2,5,6,9}$ dependiendo de la etapa clínica en que se encuentren y de lo precoz y agresivo que sea su tratamiento.
Digno de destacarse en esta revisión, es la ausencia de otras lesiones congénitas de lengua, tales como la macroglosia primaria y las ectópicas de tiroides, que se describen con relativa frecuencia. ${ }^{5}, 10$

El especialista dedicado a estos problemas debe tener un conocimiento cabal de los componentes funcionales de la lengud, correlacionando tratamiento, patología y función pre y postoperatoria, ya que ninguna otra estructura corporal presenta tal interacción entre músculo y sistema nervioso central y periférico. ${ }^{10}$ La meta del cirujano debe ser la preservación de la voz, el gusto, la sensación, el tamaño, la forma y la motilidad de la lengua, existiendo para ello una gran variedad de técnicas de glosectomía parcial, ${ }^{16}$ que pueden adaptarse al caso dado.

Es importante mencionar el rol de la fonoaudiologia en la rehabilitación de los niños que han sido sometidos a algunos de los procedimientos quirúrgicos linguales, más aún, si ya previamente presentaban algún déficit de fonación, a consecuencia de sil patología tumoral.

\section{RESUMEN}

Se presentan $y$ analizan lesiones tumorales benignas y malignas de lengua en niños, atendidos en un lapso de cinco años, en el Servicio de Cirugía Pediátrica del Hospital Exequiel González Cortés.

Se llama la atención sobre la riqueza de patología encontrada, la que incluye un rabdomiosarcoma de lengua, lesión poco descrita y que ha sido tratada con buen resultado.

Se enfatiza en la preservación de la función lingual en niños que deben ser sometidos a cirugia y la importancia que tiene el estudio anátomopatológico de toda tumoración lingual.

Por último se insiste en el importante papel que tiene el fonoaudiólogo en la rehabilitación de estos niños.

\section{REFERENCIAS}

${ }^{1}$ Bhaskar, S.N. Oral tumours of infancy and childhood: Asurvey of 293 cases. J. Pediat 63: 195, 1963.

${ }^{2}$ Dunaidson, S.S. et al. Rhubdomyosarcoma of head and neck in children: combination treatnent by surgery, irradiation and chemotherapy, Cancer 31:26, 1973.

${ }^{3}$ Grabb, W.C. and Smith, J.W. Cirugía Plástica. Ed. Salvat, 1970.

${ }^{4}$ Jones, J.H. Soft tissue aral tumours in children: their structu- 
re, histogenesis and bebaviour. Proc Roy Soc Med 59: 673, 1966.

5 Jones, P.G. and Camphell, P.E. Tumours of infancy and childhood Blackwell, 1976.

6 Liebert, P.S. et al. Rhabdomyoxarcuma of the tongue in an infant. Results of combined radiation and chemotherapy. Ann Surg 178: 621, 1973.

7 Nelson, W.E. et al. Tratado de pediatria. Ed. Salvat, 1971. s Solomon, M.P.et al. Lingual Rhabdomyoma (Adult variant) in a chid. J. Pediatr 5urg. 14: 91, 1979.

${ }^{9}$ Sutow, W.W. et al. Clinical Pediatric Oncology. The C.V. Musby Company, 1977.

10 Velcek, F.T. et al. Tongue lesions in children. J Pediatr Surg. 14: $238,1979$.

II Weitz, $\boldsymbol{l}$ et al. A bloodless technigue for tongue surgery. Head \&c Neck Surg. 3: 244, 1981. 